論文

항공사 안전관리시스템에 대한 조종사의 인식과 안전행동에 대한 연구

조성환*, 김기웅**, 박성식***

\title{
An Analysis on the Cockpit Crews' Perception on Airline's Safety Management System and their Safety Behavior
}

\author{
Sung Hwan Cho*, Ki Woong Kim** and Sung Sik Park***
}

\begin{abstract}
This paper has tried to research the perception of pilots in a commercial airliners or full service carriers focusing on the airliner's safety management system (SMS). ICAO requires the airliners to set up the basic standards of SMS since the SMS is believed to be the core of the aviation risk management. According to the previous study, it was proved safety climate of an airline affects the safety behavior of cockpit crews. Safety climate is different from safety culture and the safety climate has an advantage to be measured more quantitatively than the culture. That is, the safety climate could be represented as SMS.

As the results of the empirical study based on Chen \& Chen(2014)'s SMS practice sacle, it had been assumed at the beginning the major factors such as Clarification of SMS, Safety Training for Crews and Sharing of SMS Information have positive effects on the motivation for safety behaviors. The motivation is directly correlated to crews' safety behaviors. However, the result showed the clarification of SMS has not a significant effect on their safety behaviors. The main reason is cockpit crews, through the survey, perceived airline seemed to have no definite standards of SMS and the senior management to have less interest in aviation safety.
\end{abstract}

Key Words : Safety Culture(안전 문화), Safety Behavior(안전행동), Safety Management System(안 전관리시스템), Safety Motivation(안전 동기), Safety Climate(안전 환경)

\section{1. 서 론}

항공운송산업에 있어서 수백여 명의 승객 및 항공기체의 안전 보장은 운항승무원인 조종사들 의 비행교육훈련 뿐만 아니라 인성교육에 있어서 가장 중요시 되는 항목이다. 2001년부터 2010년 까지 대만의 항공안전위원회의 조사에 따르면 항 공기 사고의 $71.9 \%$ 가 Human Error에 의한 사고

2014년 06월 04일 접수 2014년 06월 18일 심사완료 논문심사일 (2014.06.11, 1차)

* 한국항공대학교 항공경영학 박사과정

** 한국항공대학교 경영학과

*** 한국교통대학교 항공운항학과

연락저자, E-mail : sungsikpark@hotmail.com

충청북도 충주시 대학로 50
였으며 이 중에서 $46.9 \%$ 는 조종사에 의한 안전사 고였던 것으로 분석되었다[15]. 따라서 조종사의 안전행동에 영향을 미치는 요인들이 무엇인지 규 명하고 이러한 요인들이 잠재해 있는 항공사 조 직의 안전 환경을 분석하는 것이 매우 중요하다. 항공기 조종사의 Human Factor에 의해 유발되 는 안전사고 관련 선행연구는 국내외에서 다양한 측면(조종사의 리더십, 팀워크, 자기효능감 및 조 종사 과실 등)에서 진행되었다.

그러나 조종사가 종사하는 항공사, 즉 조직의 측면에서 조종사의 안전행동에 영향을 미치는 요 인을 분석한 선행연구들은 흔하지 않다. 예를 들 어, Cooper \& Phillips(2004) 및 Fogarty \& Shaw (2010)은 항공사 조직의 안전 환경(Safety Climate) 은 조종사 개개인의 안전행동에 핵심적인 영향을 미친다고 주장했다[6,9]. 선행연구들을 살펴보면 
Table 1. 2000년대 이후 주요 항공기 안전사고

\begin{tabular}{|c|c|c|}
\hline 일 자 & 항공기 안전사고 & 비 고 \\
\hline 2014.04.28 & $\mathrm{B} 767$ 아시아나 항공 엔진오일 경고등 무시 후 사이판 비행 & \\
\hline 2014.02.17 & B767-300ER 에티오피아 항공 부기장 망명시도 스위스 비상착륙 & \\
\hline 2014.03 .24 & 말레이시아 항공. 쿠알라룸푸르 이륙 1시간 후 실종 & \\
\hline 2013.04 .13 & B737 Lion 항공. 발리 덴파사 공항에 접근 중 바다에 추락 & \\
\hline 2013.07.06 & $\mathrm{B} 777$ 아시아나 항공. 샌프란시스코공항 착륙 中 활주로와 충돌 & \\
\hline 2013.08 .14 & Airbus 777A300F4 UPS항공. 버밍햄 공항에 착륙 중 활주로와 충돌 & 화물기 \\
\hline 2013.10 .16 & ATR-72-212A 라오항공. Pakse공항 접근중 기상악화로 메콩강에 추락 & \\
\hline 2013.11 .17 & B737 Tatarstan 항공. 러시아 카잔공항에서 Go-Around 중 추락 & \\
\hline 2009.06 .01 & A300-200 에어프랑스. 대서양 상공에서 번개에 의한 오작동으로 추락 & \\
\hline 2012.06 .03 & MD-83 Dana 항공. 무탈라 공항에 접근중 Lagos 교외지역에 추락 & \\
\hline 2012.04 .20 & B737 Bhoja 항공. 파키스탄 상공에서 기상악화로 추락 & \\
\hline 2011.11 .01 & B767 LOT Polish 항공. 워쇼공항에서 Landing gear down 실패 & \\
\hline 2011.10 .18 & B727 Iran 항공. Mehrabad 공항에서 Nose gear 없이 착륙 후 충돌 & \\
\hline 2011.07 .30 & B737 Caribbean 항공. Cheddi 공항에서 활주로 Overrun & \\
\hline 2011.07 .08 & B747-400F 아시아나 항공. 제주도 상공 화재 후 회항 중 추락 & 화물기 \\
\hline 2010.08 .16 & B737-700 AIRES 항공. 구스타보 공항에서 Hard landing 후 폭발 & \\
\hline 2010.05 .22 & B737-800 Air India Express Mangalore 공항에서 활주로 Overrun & \\
\hline 2010.05 .12 & A330 아프리키야 항공. Tripoli 공항에서 착륙 중 추락 & \\
\hline 2010.01 .25 & B737-800 에티오피아 항공. 지중해 공해상에서 추락 & \\
\hline 2010.01 .24 & Tu-154 Taban 항공. 응급환자로 인한 비상착륙 중 Mashhad 공항 추락 & \\
\hline 2009.12 .25 & A300-300 Northwest 항공. 소형 폭발물에 의한 테러 & \\
\hline 2009.06 .01 & A330-200 에어프랑스. 대서양 공해상에서 추락 & \\
\hline 2009.02 .25 & B737-800 터키항공. Final approach 도중 지반과 충돌 & \\
\hline 2009.01 .15 & A320 US Airways 항공. Bird Strike로 인한 허드슨 강 불시착 & \\
\hline 2008.09 .14 & B737 Aeroflot Flight. perm 공항에 접근도중 추락 & \\
\hline 2008.08 .20 & MD-82 Spanair Flight. Barajas 공항에서 이륙 중 추락 & \\
\hline 2008.06 .10 & A310 Sudan Airways 항공. Khartoum 공항에서 추락 & \\
\hline 2007.05 .05 & B737-800 Kenya Airways 항공. Douala에서 추락 & \\
\hline 2007.01 .01 & B737-400 Adam 항공. 인도네시아 Sulawesi 섬 인근에서 추락 & \\
\hline 2006.05 .03 & A320 Armavia 항공. 흑해 연안에서 추락 & \\
\hline 2005.10 .22 & B737-200 Bellview 항공. Lagos에서 이륙 후 추락 & \\
\hline 2005.09 .05 & B737-200 Mandala 항공. Medan에서 추락 & \\
\hline 2005.08 .02 & A340-300 Air France. 활주로에서 Skids off 후 화재 & \\
\hline 2004.01 .03 & B737-300 Flash 항공. 적해에서 추락 & \\
\hline 2003.07 .08 & B737-200 Sudan 항공. 수단에서 이륙 후 추락 & \\
\hline 2002.05 .25 & B747 China Airline 공중 폭발 후 대만해협 추락 & \\
\hline 2001.11 .12 & A300 아메리칸 항공 뉴욕 JFK 공항 이륙 후 퀸즈에 추락 & \\
\hline
\end{tabular}

안전 환경은 안전 문화(Safety Culture)와 다른 개념으로 구분되는 것을 확인할 수 있다. 안전 문화는 조직차원에서 즉, 항공사라는 기업 문화 의 일부이며 심리적인 특성이 강해 정량적으로
측정하기 쉽지 않은 특성을 갖는다.

하지만 안전 환경은 안전 문화보다 협의적인 개념이다. 따라서 조종사 관점에서 조종사가 인 식하는 항공사 안전 문화를 조종사의 안전 환경 
이라고 정의할 수 있다[14]. 따라서 항공사 조직 으로 한정하면 조종사를 대상으로 한 정량적인 측정이 상대적으로 용이하다.

Table 1은 뉴스기사를 통해 접한 2,000년대 주 요한 항공기 안전사고들을 연구자가 정리한 표이 다. 상기 표를 통해 확인 할 수 있듯이 테러 혹 은 Bird Strike을 제외한 대부분의 항공기 사고가 Take-off, Approaching, Landing, Taxing, Overrun 혹은 착륙복행 때 발생하였으므로 특별한 기체 결함이 판명되지 않은 경우 조종사에 기인한 사 고들이다. 대부분 조종사 개인과실에 사고조사가 집중되었다. 그러나 조직 측면에서 항공사의 안 전관리시스템(SMS)에 대한 관심은 상대적으로 높지 않았다.

따라서 연구자는 항공사라는 조직관점에서 항 공사의 안전관리시스템에 대한 조종사의 인식을 분석하여 항공기 조종사의 안전행동에 영향을 미 치는 요인을 규명할 것이다. Zohar(1980)1)의 연 구를 토대로 안전관리시스템은 조종사가 인식하 는 안전 환경으로 판단할 수 있으며 정량분석이 용이하기 때문이다[18].

\section{2. 본 론}

\section{1 조직행동론(Organizational Behavior)}

조직의 관점에서 개인에게 미치는 영향을 살 펴보는 이론이 조직행동론이다. 조종사도 항공사 의 조직구성원이므로 조직행동론은 항공사에도 적용가능한 이론적 툴(tool)의 역할을 할 것이다.

조직행동론은 조직의 구조와 기능을 이해하고 조직에 속한 집단과 개인의 행동을 연구하는 학 문을 의미한다. 조직행동론의 탄생은 1900년대 초로 거슬러 올라간다. 1900년대 초 현대 산업사 회로의 진입과 함께 학문으로 정립되기 시작한 경영학과 경제학이 '생산'의 측면에만 집중하면서 인간의 사회적 특성을 무시한다는 비판을 받아왔 다. 1930년대 이후 비대해지는 조직을 어떻게 보 다 효율적이고 조직적으로 통제할 수 있을지 고 민하면서 조직행동론에 대한 관심이 커졌다.

조직행동론은 조직(회사)과 개인의 측면을 균 형 있게 다루기 위한 조직의 경영 및 관리 방향 을 제시하고자 탄생하였다. 왜냐하면 조직행동론 은 조직측면에서 조직의 특성과 기능을 이해하면 서 동시에 개개인의 심리와 행동을 연구하는 학 문이기 때문이다. 조직행동론은 크게 미시적(Micro) 조직행동론과 거시적(Macro) 조직행동론으로 구 분할 수 있다. 미시적 조직행동론은 집단 내에서
개별 구성원의 리더십, 동기부여, 의사소통 등을 다루지만 거시적 조직행동론은 조직의 구조, 조 직의 변화 및 조직이 처해 있는 환경 등을 주요 연구대상으로 삼는다. 이렇듯 조직원들 개개인의 행동을 조직의 목표와 비전에 맞는 방향으로 변 화시키기 위해 개인행동을 이해하기 위한 심리학 적 연구 내용도 포함되어 있는 학문이다. 또한 조직 구성원에서부터 집단 그리고 회사 전체의 조직수준까지 연구하여 조직을 관리하기 위한 정 책적 시사점을 제시하기 때문에 조직행동론 연구 는 경영학, 경제학, 인문학 및 정치학까지 폭넓게 이론연구를 진행하는 경우가 많다.

본 연구의 대상이 된 민간항공사 조종사의 경 우 항공사의 조직구성원으로서 승객들의 안전과 운항승무원 및 객실승무원 팀을 관리하면서 항공 기의 효율적인 운항을 모두 책임지고 있기 때문 에 조직행동론의 관점으로 연구하기에 가장 최적 의 대상이라고 판단하였다. 아울러 조종사를 대 상으로 한 선행연구의 대부분이 민간항공기 조종 사보다는 일반항공(General Aviation) 분야 조종 사를 대상으로 한 경우가 많았기 때문에 조직행 동론을 적용하기 쉽지 않았다[16,13].

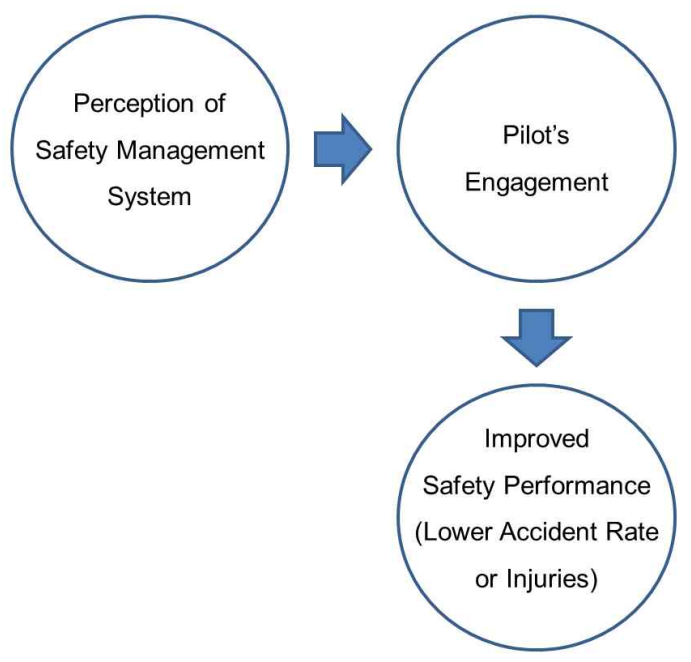

Fig. 2 안전관리시스템 개념도

상기 Fig. 1은 인간의 행동은 인간이 가진 지 식과 가치뿐만 아니라 개개인이 처한 조직문화와 조직의 규범으로부터 발생된다는 Bill(2003)의 개 념도를 조종사가 인식하는 안전관리시스템에 맞 게 발전 적용시킨 모형이다[5].

1) Safety climate is a term used to describe shared employee perception of how safety management is being operationalized in workplace (Zohar, 1980) 
조종사의 안전행동은 미시적으로는 승객의 안 전과 직결되지만 거시적으로는 항공사의 운항안 전 기록 및 항공사 기업 전체의 평판과도 직결되 기도 한다. 따라서 조종사의 안전행동에 영향을 미치는 요인을 항공사 조직의 관점으로 분석하는 것은 큰 의의가 있다.

따라서 항공사의 안전관리시스템에 대한 조종 사의 인식은 곧 조직행동론의 관점에서 주된 연 구대상이 될 수 있다. Chen \& Chen(2014)은 항공 사의 안전관리시스템은 기업으로서 항공사의 안 전 정책과 항공기 안전을 어떻게 효율적인 기업 운영지표와 결부시키는 지 보여주는 회사 경영정 책의 상징적인 지표라고 주장하기도 했다. 그들 은 또한 항공사 안전관리시스템은 조직(항공사) 수준 및 개개인(조종사) 수준에서 동시에 안전도 를 평가할 수 있는 지표라고 언급했다[7].

\section{2 항공사의 안전관리시스템}

기업들은 기업의 최상의 안전도 유지 혹은 안 전도 향상을 위하여 행태(Behavior-based) 분석에 초점을 둔 안전관리시스템을 채택해왔다. 행태분 석 관점에서 기업은 회사의 비전과 목표 등을 안 전관리시스템을 설계하는 데 반영하며 노동자는 그러한 가치들을 실현한다. 즉 노동자들은 안전 관리시스템을 인식하면서 근로환경 속에서 상기 가치들을 교감하게 되는 것이다.

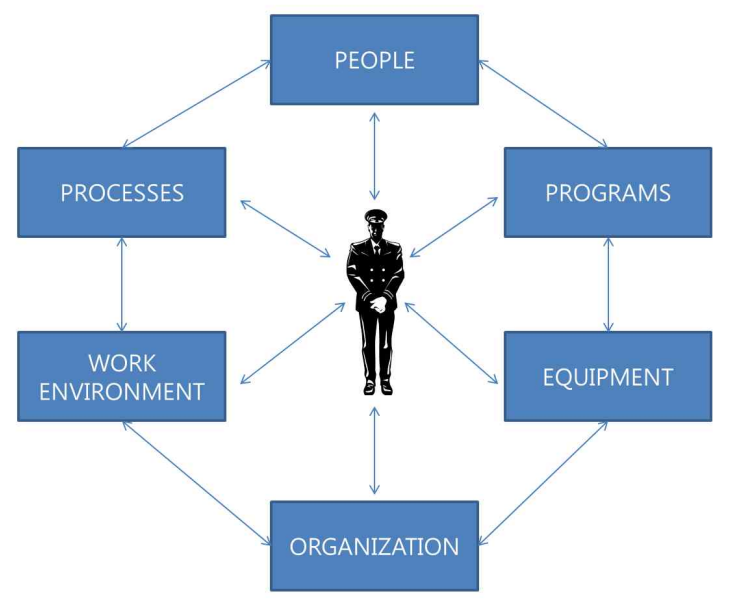

Fig. 3 안전관리시스템 구성요인

Fig. 2와 같이 항공사라는 조직의 구성원인 조 종사는 다양한 조직의 요인들에 영향을 받는다. 따라서 조종사의 안전행동은 조종사를 둘러 싼 안전 환경에 영향을 받을 것이고 이런 안전 환경 은 곧 항공사의 안전관리시스템에 대한 인식이라
고 바꿔 표현할 수 있다. 일례로 항공기 사고가 발생하면 사고현장에 있었던 조종사들은 항공사 고 조사 시 항공법, 정부 및 항공사가 요구하는 안전관리시스템을 철저히 인지하고 준수했는지 여부를 가장 먼저 조사받게 된다.

Watcher \& Yorio(2013)은 연구결과를 토대로 근로자가 인식하는 안전관리시스템은 안전행동에 긍정적인 영향을 미친다는 것을 실증했다. 실제 로 근로자가 안전관리시스템을 인식하는 정도가 높을수록 준수율이 높아지게 되어 곧 일터의 안 전사고율이 낮아지게 된다[17].

Fisher(2012)는 안전관리시스템은 지속적인 안 전관리뿐만 아니라 이러한 안전관리의 실행을 뒷 받침하는 $4 \mathrm{P}$ (Program, Process, Policy 및 Procedure) 로 구성된다고 언급하였다. 특히 조직구성원이 안전관리시스템의 중심에 있음을 강조하였다[8].

그는 안전관리시스템에 대한 연구를 통해 조 직구성원의 안전행동 분석이 가능하고 이는 곧 안전사고 예방으로 직결될 수 있다고 주장하였 다. 왜냐하면 안전관리시스템의 목적은 위험 통 계에 근거하여 사고를 예방하고자 함이기 때문이 다[4].

\section{3 조종사의 안전관리시스템 인식}

조종사들이 인식하는 안전관리시스템은 곧 조 직 관점에서 조종사의 안전행동에 영향을 주는 잠재요인이다. 항공사의 안전관리시스템은 과거 의 항공기 사고 데이터 수집 및 통계분석, 안전 운항 리스크 및 리스크 관리, 항공기 사고조사 결과분석, 안전훈련, 감사 등 다양하게 구성된다.

미국연방항공청(FAA)2)는 항공사의 안전관리시 스템은 항공기 사고 위험성을 사전에 통제하고 예방하기 때문에 안전한 비행 환경을 제공하는 질적 경영접근법(Quality Management Approach)이라 고 정의했다.

항공사의 안전관리시스템은 조종사 개인보다 는 회사 전체가 하나의 팀으로 항공기와 승객의 안전을 최우선시 하는 것을 강조한다. 항공사는 이러한 전사적인 관리 시스템을 통해 안전사고가 발생하기 전에 항공기의 안전을 저해하는 요인들 을 발견하고 제거하고자 한다[11]. 안전관리시스 템이 정착하기 위해서는 항공사 조직구성원들은 자신의 위치에 따라 다음과 같은 역할이 요구되 어 진다[10].

2) Federal Aviation Administration, 2006, Introduction to Safety Management System for Air Operation, No: AC 120-92 


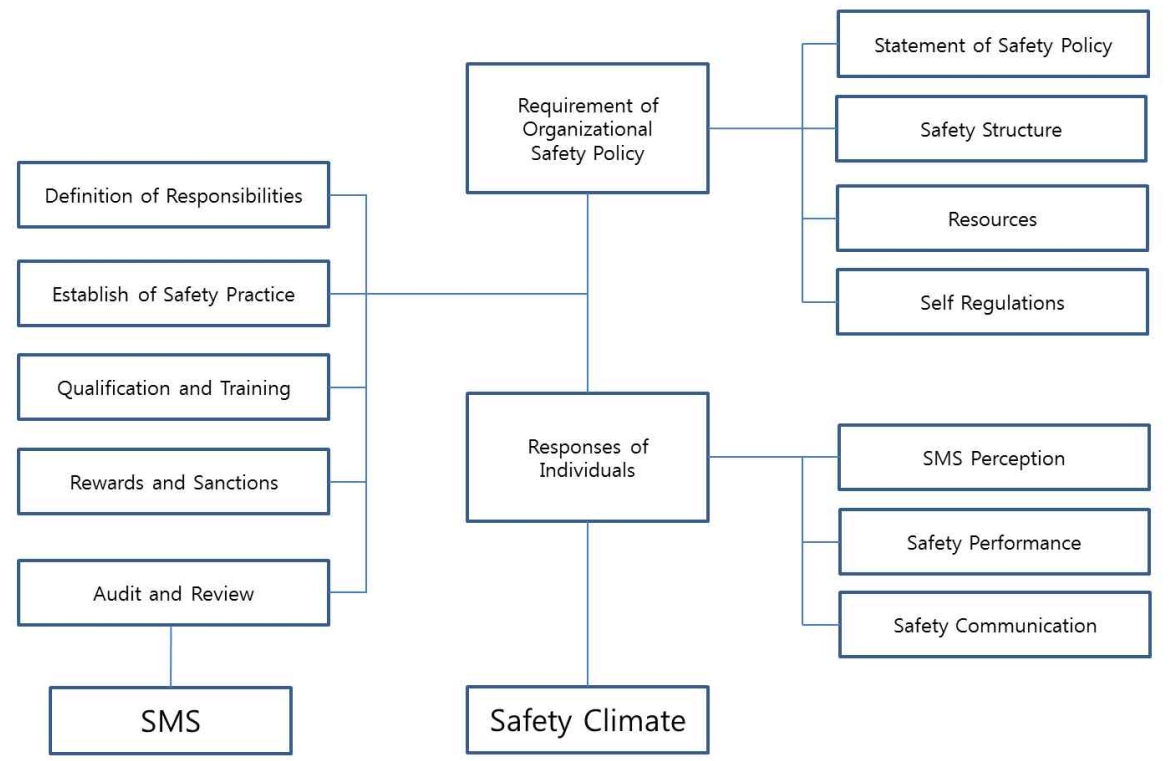

Fig. 3 안전관리시스템과 안전 환경 (Si-Hao et al., 2008)

1) 경영진 : 안전관리시스템의 주요 구성요인 선정 및 점검

2) 관리자 : 다양한 차원의 안전관리시스템 프 로세스 정립

3) 실무자 : 안전관리시스템에 따른 효과적인 교육 및 실무 적용

상기 Galottie et al.(2006)가 주장한 조직구성 원의 역할을 항공사 조종사에게 적용시켜보면 다 음과 같다. 즉, 조종사들이 안전관리시스템을 인 식하는 수준은 결국 조종사들이 자신이 종사하는 항공사의 최고 경영진이 얼마나 안전을 최우선적 으로 중요시하는 가에 대해 인지하고 항공사가 부서의 경계를 넘어 조직적인 차원에서 안전사고 를 대비하기 위해 주기적으로 안전관리시스템을 업데이트 하고 대내외 정책변화에 맞게 시스템의 기준을 적용하는 등 항공사 차원에서 적절한 노 력을 하는 지를 인지하는 정도이다.

따라서 본 연구는 항공사의 안전관리시스템이 조종사의 안전행동에 조직행동론 관점에서 어떠 한 영향을 미치고 있는 지를 Chen \& Chen (2014) 안전관리시스템 실증척도 (SMS Practice Scale)을 활용하여 정량적으로 측정하고자 하였다[7].

항공사의 안전관리시스템은 2009년부터 ICAO 에서 의무적으로 이행하도록 하는 권고사항3)이
며 운항안전과 관련된 조종사의 인적 요인은 사 전 조치 및 통제가 어려운 반면 정책적 차원에서 항공사의 안전관리시스템은 개선 및 보완이 가능 하므로 안전사고 예방에 효과적이기 때문이다 [1,3]. 아울러 항공사의 안전관리시스템에 대한 조종사의 인식수준이 높을수록 시스템 준수율이 높아져 안전행동에 대한 동기부여는 더욱 강해질 수 있기 때문에 이러한 인식수준은 조종사의 궁 극적인 안전행동에 직·간접적으로 긍정적인 영향 을 주는 요인이 될 수 있다[7].

\section{3. 연구설계}

\section{1 연구방법}

본 연구에서는 실증적 연구를 위하여 Chen \& Chen (2014)의 안전관리시스템 실증척도를 조직 행동론 관점에서 국내 조종사들의 실정에 맞게 발 전·적용하였다[7]. 안전관리시스템 실증척도는 총 23개의 설문문항으로 구성되어 있으며 본 연구자 는 기존의 5점 척도를 7 점 척도로 세분화하였다.

안전관리시스템은 이미 다양한 산업분야에서 적용되고 있다. 따라서 항공운송뿐만 아니라 제 조업 및 건설업 등의 Safety Science 관련 국내외

3) ICAO Safety Management Manual Doc 9859 : This manual also provides guidance material for the establishment of SMS requirements by States as well as for SMS development and implementation 
선행논문 등을 활용하여 안전관리시스템에 대한 인식 수준과 안전행동 간의 인과성에 대한 검토 를 하였다. 본 연구에서는 국내의 양대 국적사인 $\mathrm{K}$ 사와 $\mathrm{A}$ 사의 부기장 이상급 조종사들에게 배포 하여 회수된 설문지를 바탕으로 실증연구를 수행 하였다. 국내에 다양한 저가항공사가 출범하여 운항 중에 있으나 최근 들어서야 자사 내 모의비 행장치를 도입하는 등 아직까지는 정규항공사(Full Service Carrier)에 비해 안전관리시스템 정착이 미흡할 것으로 판단하였기 때문이다.
해 Organizational Behavior, Safety Awareness \& Competency, Safety Precaution, Safety Communication 및 Safety Training 등에 맞는 설문문항들을 인용 하여 국내 여건에 맞는 새로운 문항과 잠재변수 들을 구성하고자 하였다[14].

안전관리시스템에 대한 인식을 묻는 설문문항 을 SPSS 통계패키지를 활용한 탐색적 요인분석 으로 분석하여 국내 조종사 환경에 맞는 잠재변 수들을 도출하고자 하였다. 앞서 언급한 Fig. 2와 같이 Watcher \& Yorio(2013)는 안전관리시스템을

Table 2. 안전관리시스템 실증척도 (Chen \& Chen, 2014)

\begin{tabular}{l|c|c}
\hline \multicolumn{1}{c|}{ SMS Practice Scale } & Mean & Std. Dev. \\
\hline$\cdot$ Continuously improves the SMS practice & 4.44 & 1.25 \\
\hline$\cdot$ Precise standard of the SMS practice & 5.84 & 1.16 \\
\hline$\cdot$ Internal reporting channel is highly accessible & 4.98 & 1.48 \\
\hline$\cdot$ Top management participates & 4.18 & 1.59 \\
\hline$\cdot$ Following the principles of fairness and justice & 4.88 & 1.44 \\
\hline$\cdot$ Clearly stated its determination to execute SMS & 5.57 & 1.24 \\
\hline$\cdot$ Declares commitment in formal documents & 5.45 & 1.36 \\
\hline$\cdot$ Employees are acquainted with safety plans & 6.15 & .936 \\
\hline$\cdot$ Employees periodically take training programs & 6.24 & .891 \\
\hline$\cdot$ My company periodically runs drills to practice plans & 5.24 & 1.48 \\
\hline$\cdot$ Establishes emergency preparedness and response plans & 5.23 & 1.39 \\
\hline$\cdot$ Managers order clear commands for safety & 5.37 & 1.12 \\
\hline$\cdot$ The contents of the SMS manual are readily understood & 5.53 & 1.22 \\
\hline$\cdot$ Intranet system can precisely handle the safety information & 5.58 & 1.09 \\
\hline$\cdot$ Intranet system used as the platform to share safety information & 5.57 & 1.12 \\
\hline$\cdot$ Documents are preserved and continuously updated & 5.19 & 1.26 \\
\hline$\cdot$ Establishes simple and unified standard & 5.59 & 1.09 \\
\hline$\cdot$ Employees upgrade abilities through safety training programs & 5.57 & 1.18 \\
\hline$\cdot$ Employees learn concepts through safety training & 5.48 & 1.23 \\
\hline$\cdot$ Company continuously provides safety training programs & 5.49 & 1.20 \\
\hline$\cdot$ Employees know way to execute SMS through safety training & 5.44 & 1.05 \\
\hline$\cdot$ Company provides diverse safety training programs & 5.98 & 1.35 \\
\hline$\cdot$ My company holds SMS promotion activities regularly & 5.24 & 1.06 \\
\hline
\end{tabular}

정량분석을 위해 코딩된 설문지는 SPSS 20.0을 활용하였다. 가설검증을 위한 실증분석은 구조방 정식(SEM) 모형을 이용하였다. 통계패키지 AMOS 20.0 을 사용하였다.

\section{2 연구모형}

본 연구에서는 실증분석을 위해 안전관리시스 템을 구성하는 설문항목들을 항공사라는 회사 조 직의 관점뿐만 아니라 Fig. 3의 안전 환경까지 고려하여 적용하였다. 측정문항은 선행문헌을 통
구성하는 잠재변수들은 과거 관련 선행문헌연구 를 통해 Employee Involvement, Safe Work Procedure, Corporate Facilitation, Safety Training, Information Sharing, Communication, Training, Detection \& Monitoring 등 연구자에 따라 다양하게 구성되 었다고 주장하였다[17].

종속변수로서 조종사의 안전행동을 묻는 설문 문항은 Neal \& Griffin(2006)의 연구내용을 인용 하였다[12]. 그들은 개인과 조직(팀) 간의 안전행 동 차이를 비교·연구하였다. 팀원의 안전수칙 준 수뿐만 아니라 비행 중 안전을 담보하기 위한 환 
경조성을 위한 팀워크 참여활동까지 안전행동의 범주에 포함된다고 주장하였다. 사업용 항공기를 운항하는 조종사는 기장과 부기장이라는 운항승 무원뿐만 아니라 객실의 승객안전을 책임지는 객 실승무원들과 함께 팀을 이루어 비행한다는 측면 에서 상기 논문의 설문문항을 적용하기에 무리가 없다고 판단하였다. 이에 따른 연구모형은 Fig. 4 와 같이 설정하였다. 독립변수를 구성하는 3 개의 잠재변수들의 도출과정은 4 장 실증분석에서 자세 히 언급하기로 한다.

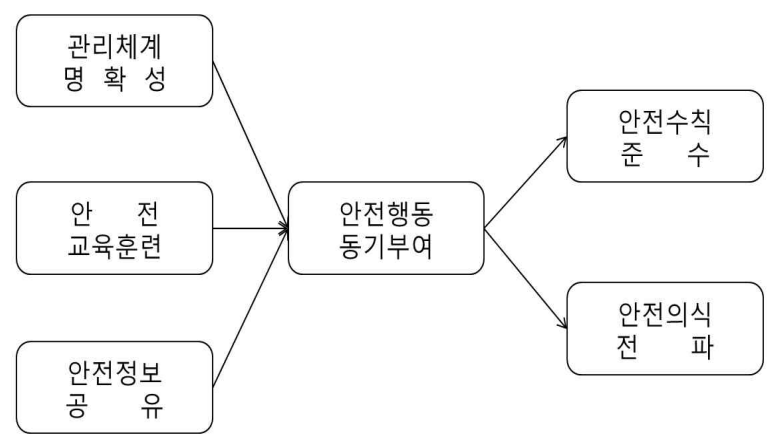

Fig. 4 연구모형

\section{3 연구 가설}

Fig. 4 의 연구모형과 관련하여 항공사의 안전 관리시스템에 대한 명확한 관리수준은 실질적으 로 많은 조종사들의 동기부여수준에 영향을 미칠 것이고 이는 궁극적으로 안전참여행동 즉 안전참 여행동에 영향을 미칠 것이라는 것을 바탕으로 도출한 것이다. 본 연구에서는 실증분석에 앞서 실시한 탐색적 요인분석 결과를 바탕으로 안전관 리시스템을 구성하는 요인들을 관리체계의 명확 성, 안전교육훈련, 안전정보 공유라는 3 개의 잠재 변수들로 구분하여 활용하였다. 이 잠재변수들은 조종사의 안전행동 동기부여를 매개로하여 안전 수칙 준수 및 안전의식 전파에 영향을 미칠 것이 라고 판단하였고 이를 바탕으로 연구 가설들을 아래와 같이 설정하였다.

가설 1. 항공사 안전관리시스템에 있어 관리체계의 명확성은 조종사의 안전행동 동기부여에 정 $(+)$ 의 영향을 미친다.

가설 2. 항공사 안전관리시스템에 있어 안전교육 훈련 수준은 조종사의 안전행동 동기부여 수준에 정(+)의 영향을 미친다.
가설 3. 항공사 안전관리시스템에 있어 안전정보의 공유 수준은 조종사의 안전행동 동기부여 수준에 정(+)의 영향을 미친다.

가설 4. 항공사 안전관리시스템에 있어 조종사의 안전행동 동기부여는 안전수칙 준수에 정 $(+)$ 의 영향을 미친다.

가설 5. 조종사의 안전행동 동기부여는 안전의식 전파에 정 $(+)$ 의 영향을 미친다.

\section{4 조사 대상 및 방법}

본 연구의 실증분석을 위하여 국적 정규항공사 (Full Service Carrier)인 K항공사와 A항공사에 종사하는 조종사들을 대상으로 하였다. 조사기간 은 2014년 4월 1일부터 4월 26일까지 약 25일에 걸쳐, 다양한 비행시간 경력을 가진 조종사 중 기장, 부기장, 기타 등의 직급을 가지고 있는 Cockpit Crew들을 대상으로 실시되었다. 총 300 부를 배포하여 유효 설문지 244부를 회수하여 약 $81.3 \%$ 의 회수율을 기록하였다.

\section{5 자료 분석 방법}

응답자의 인구통게학적 분석을 위해 빈도분석을 실시하여 응답한 조종사들의 현황을 살펴보았다. 아울러 신뢰성 분석을 위해서 Cronbach's a 계 수를 이용하여 설문문항(측정도구)의 신뢰성을 파악하였다. 실증을 위한 구조방정식 분석에 앞 서 확인적 요인분석을 실시하였으며 각 경로 간 가설검증을 위해 각 잠재변수들, 매개변수, 결과 변인 간의 경로를 설정하고 각각의 경로마다의 표준화계수 및 요인부하량의 의성 등에 대한 경 로 분석을 실시하였다.

\section{4. 실증분석}

\section{1 표본의 인구통계적 특성}

\subsection{1 응답자 특성}

Table 3에 나타낸 바와 같이, 남성과 여성 분 포를 살펴보면 남성의 경우 241 명으로 전체의 $99 \%$ 를 차지하였고 여성은 3명을 차지하였으며, 연령과 관련해서는 31 세 40 세 90명, 41 세 50 세 108 명으로 전체 중 31 50세가 차지하는 비중이 $81.1 \%$ 를 차지하는 것으로 나타났다. 
조종사의 비행경력과 관련해서는 1 년 미만 13 명, 1 5년 63명, 5 10년 26명, 10년 이상 142명 으로 10 년 이상의 경력자의 응답비율이 가장 높 은 것으로 나타났다. 비행시간과 관련해서는 1 2천 시간이 38 명, 2 5천 시간이 50명, 5천 시간 이상이 119 명으로 5 천 시간 이상의 비행시간을 가지고 있는 응답자의 비중이 가장 높은 것으로 나타났다. 직급과 관련해서는 기장 122 명, 부기장 105 명, 기타 17 명으로 나타났다.

Table 3. 인구통계학적 특성

\begin{tabular}{|c|c|c|c|}
\hline 구분 & 항목 & 응답수 & 비율 \\
\hline \multirow{2}{*}{ 성 별 } & 남 성 & 241 & 99.0 \\
\hline & 여 성 & 3 & 1.0 \\
\hline \multirow{4}{*}{ 연 령 } & 30대 미만 & 5 & 2.1 \\
\hline & 31세 40세 & 90 & 36.9 \\
\hline & 41세 50세 & 108 & 44.2 \\
\hline & 51세 이상 & 41 & 16.8 \\
\hline \multirow{4}{*}{ 경 력 } & 1년 미만 & 13 & 5.2 \\
\hline & 1 5년 & 63 & 25.9 \\
\hline & 5 10년 & 26 & 10.5 \\
\hline & 10년 이상 & 142 & 58.4 \\
\hline \multirow{4}{*}{$\begin{array}{l}\text { 비 행 } \\
\text { 시 간 }\end{array}$} & 1천 시간 미만 & 37 & 15.2 \\
\hline & 1 2천 시간 & 38 & 15.4 \\
\hline & 2 5천 시간 & 50 & 20.7 \\
\hline & 5천 시간 이상 & 119 & 48.7 \\
\hline \multirow{3}{*}{ 직 급 } & 기 장 & 122 & 50.0 \\
\hline & 부기장 & 105 & 43.2 \\
\hline & 기타(S.O 및 교관) & 17 & 6.8 \\
\hline
\end{tabular}

\subsection{2 신뢰성 검증}

측정도구의 내적 타당성(신뢰성) 검증과 관련 하여 변수들에 대한 Cronbach's $a$ 을 활용하여 검증을 수행하였다.

Table 4. 신뢰도 측정결과

\begin{tabular}{c|c|c}
\hline 항 목 & Cronbach's a & 항목수 \\
\hline 안전관리시스템 & .859 & 23 \\
\hline 안전행 동 동기부여 & .833 & 3 \\
\hline 안전수칙 준수 & .855 & 3 \\
\hline 안전의식 전파 & .869 & 3 \\
\hline
\end{tabular}

신뢰성 분석결과 안전관리시스템에 대한 23개 설문문항, 안전행동 동기부여 및 조종사의 안전행 동 관련 모든 설문문항들에서 모두 수용가능 수준 인 0.7 보다 높은 Cronbach's a 값을 보이고 있 는지를 판단하였다. 분석 결과 전 문한에서 신뢰
성 수준이 0.7 보다 높게 나타나 측정도구의 신뢰 성에는 문제가 없는 것으로 판단하였다.

\subsection{3 타당성 검증}

본 연구에서의 안전관리시스템을 구성하는 잠 재변수들의 확인적 요인분석에 앞서 SPSS를 활 용한 탐색적 요인 분석을 수행하였다. 탐색적 요 인분석 결과 공통성은 모두 0.4 이상으로 나왔으 며, 요인은 Fig. 4의 모형에서 가설로 세운 것과 동일하게 3 개의 요인으로 나타났다. 요인 1 은 관 리체계의 명확성으로 총 8 개의 설문문항으로 구 성되었으며, 요인2는 안전교육훈련으로 총 4 개의 설문문항 그리고 요인3은 안전정보의 공유로서 총 3 개의 문항으로 구성되었다.

Table 4. 안전관리시스템 요인분석결과

\begin{tabular}{|c|c|c|c|c|}
\hline & 설문문항 & 요인 1 & 요인2 & 요인3 \\
\hline \multirow{8}{*}{$\begin{array}{c}\text { 관리 체 계 } \\
\text { 명 확성 }\end{array}$} & 설문문항 5 & .821 & .095 & .327 \\
\hline & 설문문항 3 & .804 & .126 & .127 \\
\hline & 설문문항 19 & .633 & .424 & .252 \\
\hline & 설문문항 11 & .728 & .209 & .356 \\
\hline & 설문문항 10 & .694 & .168 & .411 \\
\hline & 설문문항 17 & .669 & .352 & .325 \\
\hline & 설문문항 16 & .653 & .164 & .523 \\
\hline & 설문문항 18 & .652 & .539 & .263 \\
\hline \multirow{4}{*}{$\begin{array}{l}\text { 안전교육 } \\
\text { 훈 련 }\end{array}$} & 설문문항 8 & .142 & .850 & .249 \\
\hline & 설문문항 9 & .192 & .829 & .261 \\
\hline & 설문문항 2 & .556 & .639 & .117 \\
\hline & 설문문항 7 & .166 & .455 & .430 \\
\hline \multirow{3}{*}{$\begin{array}{l}\text { 안전정보 } \\
\text { 공 유 }\end{array}$} & 설문문항 13 & .275 & .207 & .821 \\
\hline & 설문문항 14 & .268 & .186 & .804 \\
\hline & 설문문항 15 & .358 & .402 & .633 \\
\hline 통 계 량 & \multicolumn{3}{|c|}{ KMO .949 $(p=.000)$} & Bartlett 구형성 검정 6325.475 \\
\hline
\end{tabular}

\subsection{4 모형적합도 분석}

본 연구에서의 잠재변수들 간 경로를 실증하기 에 앞서 모형적합도를 판단하고자 하였다. 모형 적합도는 AMOS 20.0을 활용하여 확인적 요인분 석을 통해 확인할 수 있었다. 모형적합도는 연구 모델을 채택하느냐 기각하느냐를 결정하는 중요 한 기준이 된다[2].

이와 관련한 모형적합도 분석 결과 절대적합지 수와 관련하여 chi-square 값은 285.848(.000)인 것으로 나타나 유의함을 알 수 있다. 그 외 $\mathrm{CMIN} /$ $\mathrm{DF}$ 는 2.978 으로 3 이하의 값으로 수용할만 한 수 
준으로 나타냈다.

절대적합지수 중 GFI 계수는 .913으로서 .9이 상의 값을 나타냈다. $\mathrm{AGFI}$ 계수는 .877로 .9에 근접한 수치를 보여주었으며, RMSEA 값도 .072 로 나타났다. RMSEA는 .08 이하이면 양호하고, .1 이하면 보통인 것으로 판단한다. RMSEA는 표 본의 크기에 영향을 가장 덜 받는 장점이 있다.

반면 증분적합지수의 특성과 관련해서는 NFI, RFI, IFI, TLI, CFI 모두 0.900을 넘는 값인 .924, $.905, .948, .935, .948$ 을 각각 나타냄으로써 모형 적합도가 매우 우수함을 나타냈다.

상기 적합도 계수들을 종합적으로 볼 때 모형 의 절대적합지수 및 증분적합지수가 본 연구의 경로 간 관계를 새로이 설정하여 확인하려고 하 는데 있어 매우 적합한 수준이라고 판단할 수 있 었다. 본 연구의 모형적합도 결과는 Table 5 를 통해서 나타난 바와 같다.

Table 5. 적합도 검증결과

\begin{tabular}{|c|c|c|c|}
\hline \multicolumn{4}{|c|}{ 절대적 합지수 } \\
\hline CMIN & CMIN/DF & GFI & RMSEA \\
\hline 285.848 & 2.978 & .913 & .072 \\
\hline
\end{tabular}

\begin{tabular}{|c|c|c|c|c|}
\hline \multicolumn{5}{|c|}{ 증분적합지수 } \\
\hline $\mathrm{NFI}$ & $\mathrm{RFI}$ & $\mathrm{IFI}$ & $\mathrm{TLI}$ & $\mathrm{CFI}$ \\
\hline .924 & .905 & .948 & .935 & .948 \\
\hline
\end{tabular}

\subsection{5 경로 분석 결과}

본 연구에서 살펴보고자 한 관리능력 중 안전 관리의 명확성, 교육훈련수준, 공유수준 및 동기 부여, 안전참여 준수수준 및 전파수준 간 관계에 대한 경로분석결과를 살펴보면 Table 6와 같다.

첫째 가설 1 과 관련하여 안전운항 관리체계의 명확성이 동기부여 수준에 정의 영향을 미친다는 것과 관련해서는 표준화 회귀계수가 -.233 으로 $\mathrm{CR}$ 이 - 2.845로 나타났고 $95 \%$ 에서 유의하였으나 부호가 음의 관계로 나타나서 가설 검증 결과 유 의하지 않은 것으로 나타났다.

둘째, 안전교육훈련이 동기부여 수준에 정의 영향을 미칠 것이라는 가설 2와 관련해서는 표준 화회귀계수가 0.613 이고 $\mathrm{CR}$ 값이 $6.113,99 \%$ 에서 유의한 것으로 나타났다.

셋째, 안전정보 공유가 조종사의 안전행동 동 기부여에 미치는 영향과 관련해서는 표준화회귀
계수가 .115인 것으로 나타났고 $\mathrm{CR}$ 은 2.036 이고 95\%신뢰수준에서 유의한 것으로 나타났다.

안전행동 동기부여가 안전행동 중 안전수칙 준 수에 정의 영향을 미칠 것이라는 가설 4 와 관련 해서는 표준화회귀계수가 .676이고 CR은 9.290, 매우 유의한 것으로 나타냈다. 마지막으로 동기 부여가 안전행동 중 안전의식 전파에 정의 영향 을 미칠 것이라는 가설 5 와 관련해서는 표준화회 귀계수의 값이 .838 를 나타냈고 $99 \%$ 의 신뢰수준 에서 유의한 것으로 나타났다.

전체적으로 나타난 경로 분석 내용은 Table 6 과 같이 나타났으며 결과적으로 보면 가설 1 을 제외하고 가설 2 , 가설 3 , 가설 4 및 가설 5 가 모 두 $95 \%$ 신뢰수준에서 유의한 가설들인 것으로 판명되었다.

Table 6. 가설검증 결과

\begin{tabular}{|c|c|c|c|c|}
\hline & 계수 & C.R. & P & 채택여부 \\
\hline $\mathrm{H} 1$ & -.233 & -2.845 & .004 & 기각 \\
\hline $\mathrm{H} 2$ & .613 & 6.113 & ${ }^{\star \star \star}$ & 채택 \\
\hline $\mathrm{H} 3$ & .115 & 2.036 & .042 & 채택 \\
\hline $\mathrm{H} 4$ & .676 & 9.290 & $\star \star \star$ & 채택 \\
\hline $\mathrm{H} 5$ & .838 & 14.298 & ${ }^{\star * \star}$ & 채택 \\
\hline
\end{tabular}

\section{5. 결 론}

\section{1 연구의 요약}

가설 1 과 관련하여 연구자는 연구 초기에 본 논문을 통해서 안전관리시스템에 대한 조종사의 인식이 명확할수록 안전행동 준수율이 높아지고 이에 따른 안전행동 동기부여 수준에 정의 영향 을 미친다고 판단했다.

그러나 명확성이 동기부여수준에 유의하지 못 한 것으로 나타났다. 이는 안전관리에 있어서는 조종사의 안전행동 역할에 대한 명확성이 반드시 안전행동을 위한 동기부여 수준을 높이는 것은 아니라는 것을 의미한다. 다시 말해서, 국내 조종 사들에게 안전절차 등의 명확성 보다는 조종사들 의 리더십에 맡기거나 권한위임 등이 이루어질 때 오히려 조종사들의 동기부여 수준에 양의 영 향을 미칠 것이다.

아울러 설문문항에 대한 빈도분석 결과 안전관 리시스템에 대한 명확성에 대한 조종사들의 인식 
결과가 상대적으로 낮은 것으로 나타났다. 구조 방정식 모형에서 '안전관리시스템의 명확성' 이 라는 잠재변수는 설문문항 1,2 및 4 번의 관측변 수들로 구성되어 있다. 설문문항 1 번 (우리 항공 사 안전관리시스템을 지속적으로 업데이트한다), 설문문항 2번(우리 항공사는 안전관리시스템에 대한 논리적인 명확한 기준이 있다) 그리고 설문 문항 4 번(우리 항공사의 최고경영진은 안전관리 시스템에 관심이 많다)에 대한 설문결과가 타 항 목들에 비해 상대적으로 낮았다.

안전교육 훈련과 동기부여 간 관계를 살펴본 가설 2는 유의한 것으로 나타났는데 이는 교육훈 련수준이 높아짐에 따라 조종사들은 자신들의 수 행해야 하는 관리능력을 익히게 됨으로써 동기부 여수준이 높아졌다.

마지막으로 가설 3 도 유의한 것으로 나타났는 데 정보 공유의 수준이 높으면 안전관리에서의 정보 업데이트에 소홀하지 않게 됨으로써 업무수 행에서의 동기부여 수준에 긍정적인 영향을 미치 는 결과가 나타난 것이다. 가설 4 및 5도 유의 한 것으로 나타났는데 이는 동기부여수준이 높게 되면 안전참여와 관련된 절차를 명확히 이행하려 고 하고 또한 안전참여와 관련된 홍보 및 의식 고취 등을 위해 별도의 노력을 기울이게 된다는 것을 의미하는 것으로 보인다.

\section{참고문헌}

1) 강우정, 2013, "조종사를 대상으로 한 Human Error 예방제도에 대한 연구", 한국교통대학 교 논문집 48, pp.471-474

2) 우종필, 2012, "구조방정식모델 개념과 이해", 한나래 아카데미

3) 이종성, 김기웅, 박성식, 강우정, 2014, "상업항공 기 조종사의 리더십 및 자기효능감이 안전행동에 미치는 영향", 한국항공운항학회 22(1), pp. 114-123

4) 한훈희, 이강준, 2014, "안전보고제도의 면책에 대한 고찰", 한국항공운항학회 2014 춘계학술발표 대회, pp. 253-257

5) Bill, D. T., 2003, "Contributing Influences on An Individual's Attitude Towards a New Technology in The Workplace", Liquid Knowledge Group Ltd.

6) Cooper, M. D., Phillips, R. A., 2004, "Exploratory Analysis of The Safety Climate and Safety Behavior Relationship", Journal of Safety
Research 35, pp.497- 512.

7) Chen C. F., Chen S. C., 2014, "Measuring the Effects of Safety Management System Practices, Morality Leadership and Self-Efficacy on Pilots' Safety Behaviors: Safety Motivation as a Mediator", Safety Science 62, pp.376-385

8) Fisher, R., 2012, "Integrating Human Performance Concepts Into Processes, Procedures, and Analysis, In: HP Summit, March 13-14, Cleveland, Ohio.

9) Fogarty, G. J., Shaw, A., 2010, "Safety Climate and The Theory of Planned Behavior: Towards The Prediction of Unsafe Behavior", Accident Analysis and Prevention 42(5), pp.1455 - 1459.

10) Galotti, K M, Giner, E, Altenbaumer, $\mathrm{H}$ A, Ceerts, H. J., Rupps, A, Woulfe, J. M, 2006, "Making a Major Life-frame Decision: Individual Differences in Performance and Affective Reactions", Personality and Individual Differences 41, pp.629- 639 .

11) Lewis, C., 2008, "A Brief Overview of Safety Management Systems (SMS)", Flight Safety Information Journal 1, pp.2-12

12) Neal, A., Griffin, M. A., 2006. "A Study of The Lagged Relationships Among Safety Climate, Safety Motivation, Safety Behavior, and Accidents at the Individual and Group Levels", Journal of Applied Psychology 91 (4), pp.946 - 953.

13) Pauley, K, ƠHare, D., Wiggins, M, 2008, "Risk Tolerance and Pilot Involvement in Hazardous Events and Flight into Adverse Weather", Journal of Safety Research 39(4), pp.403 - 411.

14) Si-Hao Lin, Wen-Juan Tang, Jian-Ying Miao, Zhi-Ming Wang, Pei-Xi Wang, 2008, "Safety Climate Measurement at Workplace in China: A Validity and Reliability Assessment", 2012, Safety Science, 46, pp.1037-1046

15) Taiwan Aviation Safety Council, 2011 http://www. asc.gov.tw/asc/count_report_1.asp

16) Wiegmann, D. A., Taneja, N., 2003. "Analysis of Injuries Among Pilots Involved in Fatal General Aviation Airplane Accidents", Accident Analysis and Prevention 35, pp.571 577.

17) Watcher J. K., Yorio P. L., 2013, “A System of Safety Management Practices and 
Worker Enga- gement for Reducing and Preventing Accidents: An Empirical and Theoretical Investigation", Acci- dent Analysis and Prevention (7), pp.157-163

18) Zohar, D., 1980, "Safety Climate in Indus -trial Organizations: Theoretical and Applied Implications", Journal of Applied Psychology, 65, pp.96-102. 